\title{
Soft Tissue Sarcomas of Vulva
}

\author{
Irene Davos, M.D., ${ }^{1}$ and M. R. Abell, M.D., Ph.D. \\ Department of Pathology, The University of Michigan Medical Center, Ann Arbor, \\ Michigan 48104
}

Received October 22, 1975

\begin{abstract}
Fifteen cases of vulvar sarcomas were studied. The most common neoplasm was leiomyosarcoma, which also had the least favorable prognosis with a tendency to develop local recurrences and disseminated hematogenous metastases. The second most frequent sarcoma belonged to the fibrous histiocytoma group. Although they are unpredictable, they tended to be less aggressive than the leiomysarcomas. Other sarcomas encountered were fibrosarcoma, hemangiosarcoma, malignant hemangiopericytoma, epithelioid sarcoma, neurogenous sarcoma, malignant mesothelioma, and embryonal stromal sarcoma. Local recurrences were common in the series due in part to inadequate initial treatment. It was evident from the study that wide local excision or radical vulvectomy early in the disease with bilateral lymph node resection for those sarcomas that have a potential for lymphogenous metastases is the treatment of choice and gives the most favorable results. In the presence of local recurrences, aggressive surgical treatment is indicated and increases the survival rate significantly.
\end{abstract}

Sarcomas of the vulva comprise a rare and perplexing group of malignant neoplasms infrequently reported in the literature [1-12]. Considerable lack of uniformity exists in their histologic classification and nomenclature. The prognosis for patients with vulvar sarcomas has generally been poor due in part to the lack of clinical experience and to the variety of therapeutic approaches that have been employed.

In general, vulvar sarcomas have been characterized by local recurrences and frequently by death from distant hematogenous metastases. When radical excisions have been done, as opposed to other approaches, the prognoses have been better $[8,9]$. The majority of patients with extensive large lesions tend to develop multiple local recurrences within short periods of time and to die soon with distant metastases. The older literature indicated that the commonest and most ominous vulvar sarcomas were the fibromyxosarcomas [8]. However, the more recent study of DiSaia, Rutledge, and Smith [9], indicated that the most common type was leiomyosarcoma followed by rhabdosarcoma. This discrepancy can be explained by more accurate histologic classification as knowledge of soft tissue sarcomas has increased.

\section{MATERIALS AND METHODS}

The histologic material from all soft tissue sarcomas of vulva accessioned in the Department of Pathology at the University of Michigan Medical Center from 1935 to 1974 inclusive was assessed. Hematoxylin and eosin stained sections were available for all cases. In specific instances, Mallory's or Masson's trichrome,

${ }^{1}$ An Elsa U. Pardee Foundation Postdoctorate Cancer Fellow. 
silver reticulin, phosphotungstic acid hematoxylin, periodic acid Schiff, and alcian blue stains with and without hyaluronic acid digestion were employed.

The determination of malignancy was based on cellular pleomorphism, number of mitotic figures, hypercellularity, documented metastases, and the known malignant biologic behavior of particular histologic types of neoplasms. All lesions considered to be of questionable or borderline malignancy were excluded from the study, as were neoplasms that involved the vagina as well as the vulva. Clinical and survival information was available for all but one of the acceptable cases.

\section{Clinical Findings}

Fifteen cases fulfilled the criteria for vulvar sarcoma. Nine of these occurred during a period when 492 cases of primary malignant neoplams of vulva were registered for an occurrence rate of $1.8 \%$. The ages of the patients ranged from 16 to $84 \mathrm{yr}$, with an average of $46 \mathrm{yr}$.

In most cases, a rapidly growing painful mass was the major symptom (Table 1). The duration of symptoms varied from 2 months to $5 \mathrm{yr}$, with a mean of 14 months. None of the patients had received previous irradiation to the involved areas. The lesions varied from 2 to $10 \mathrm{~cm}$ in greatest diameter, and most appeared to be circumscribed. The gross morphology was not characteristic for any type of neoplasm. In only one patient did the inguinal lymph nodes appear clinically to be involved.

TABLE 1

SARCOMAS OF Vulva

\begin{tabular}{|c|c|c|c|c|}
\hline Histologic type & $\begin{array}{l}\text { Age } \\
(\mathrm{yr})\end{array}$ & Location & $\begin{array}{l}\text { Presenting } \\
\text { complaint }\end{array}$ & Duration \\
\hline 1. Leiomyosarcoma & 84 & $\begin{array}{l}\text { Posterior fourchette and } \\
\text { perineal body }\end{array}$ & Painful mass & 3 months \\
\hline 2. Leiomyosarcoma & 54 & Posterior fourchette & Painful mass & 12 months \\
\hline 3. Leiomyosarcoma & 35 & $\begin{array}{l}\text { Posterior fourchette- } \\
\text { episiotomy scar }\end{array}$ & Enlarging mass & 7 months \\
\hline 4. Leiomyosarcoma & 41 & Bartholin gland area & Rapidly growing mass & 3 months \\
\hline $\begin{array}{l}\text { 5. Leiomyosarcoma } \\
\text { 6. Malignant fibrous }\end{array}$ & 49 & Bartholin gland area & Painful mass & 4 months \\
\hline $\begin{array}{l}\text { histiocytoma } \\
\text { 7. Malignant fibrous }\end{array}$ & 45 & Left labium majus & Painful mass & 12 months \\
\hline $\begin{array}{l}\text { histiocytoma } \\
\text { 8. Dermatofibrosarcoma }\end{array}$ & 55 & Labium majus & Ulcerated protruding mass & - \\
\hline proturberans & 38 & Labium majus & Tumor nodule & - \\
\hline 9. Fibrosarcoma & 50 & Right labium majus & Pruritic mass & 10 months \\
\hline $\begin{array}{l}\text { 10. Hemangiosarcoma } \\
\text { 11. Malignant }\end{array}$ & 83 & Left labium majus & Mass & $3 \mathrm{yr}$ \\
\hline hemangiopericytoma & 16 & Clitoral area & Painful mass & 4 months \\
\hline 12. Epithelioid sarcoma [13] & 31 & Left labium majus & Painful mass & 5 months \\
\hline 13. Neurogenous sarcoma & 40 & Right labium majus & Painful mass & $5 \mathrm{yr}$ \\
\hline 14. Malignant mesothelioma & $a 38$ & Left labium majus & Enlarging mass & 3 months \\
\hline $\begin{array}{l}\text { 15. Embryonal stromal } \\
\text { sarcoma }\end{array}$ & 28 & Left labium & $\begin{array}{r}\text { Painful, rapidly } \\
\text { growing mass }\end{array}$ & 2 months \\
\hline
\end{tabular}


The commonest site of origin was the labium majus (64\%), followed by the posterior fourchette and by the deep vulvar tissues adjacent to Bartholin's gland.

The initial treatment for nine patients was local excision of the tumor mass (Table 2). In five patients the definitive treatment consisted of wide local excision or "simple" vulvectomy after excision biopsy. One patient had a radical vulvectomy and bilateral inguinal lymph node dissection.

\section{Pathologic Findings}

There were nine different histologic types of sarcoma. Leiomyosarcoma was the most common neoplasm occurring in five patients (33\%) (Table 1). There were three malignant fibrous histiocytomas, one of which represented a dermatofibrosarcoma protuberans. There was one each of the other histologic types. The one example of epithelioid sarcoma is the subject of a separate case report [13].

The five leiomyosarcomas ranged from 4 to $10 \mathrm{~cm}$ in greatest diameter. Two were located in the deep tissues adjacent to Bartholin's gland, two in the posterior fourchette, and one in the area of the posterior fourchette and the perineal body. One of the posterior fourchette tumors developed beneath a median episiotomy scar. Microscopically all tumors were composed of interlacing bundles of elongated eosinophilic cells with enlarged hyperchromatic nuclei (Figs, 1 and 2). Mitotic figures were well above the level of 10 per 10 high power fields, and there were frequent abnormal forms. Two of the original neoplasms irregularly infiltrated rather than compressed the adjacent soft tissues, and two of the four recurrent tumors were extensively infiltrative.

The three malignant fibrous histiocytic neoplasms were located in the labium majus and measured $2.5,3$, and $6 \mathrm{~cm}$ in diameter. Two appeared grossly circumscribed, and the cut surfaces were distinctly yellow. The third and largest of the three lesions was less well defined with areas of necrosis. Two of the lesions consisted of a mixture of fibroblastic and histiocytic cells with haphazardly interspersed collagen fibers (Fig. 3). The histiocytic cells had granular and vacuolated cytoplasm due to the presence of lipid. Pleomorphic neoplastic cells and bizarre tumor giant cells were frequent as were mitotic figures, many of which were atypical. The third fibrohistiocytic tumor, a dermatofibrosarcoma protuberans, was a roughly circumscribed polypoid lesion, $3 \mathrm{~cm}$ in diameter, which involved the dermis and subcutis. It consisted of narrow, elongated fibroblastic cells arranged in interlacing bundles and in some areas formed typical storiform and cartwheel structures (Fig. 4). Mitotic figures were frequent. Pleomorphic and bizarre cells and nuclei, common in the other two neoplasms, were inconspicuous in this tumor.

The one pure fibrosarcoma involved the right labium majus and was roughly circumscribed, measuring $6 \mathrm{~cm}$ in diameter. It consisted of interlacing and haphazardly arranged bundles of spindled cells with hyperchromatic nuclei and frequent mitotic figures (Fig. 5). Collagen fibers, confirmed with trichrome stains, were intimately related to the tumor cells (Fig. 6).

The hemangiosarcoma presented as a raised, roughly circumscribed lesion in the left labium majus. Microscopically it consisted in part of irregular vascular spaces containing red blood cells and formed by large atypical endothelial cells 


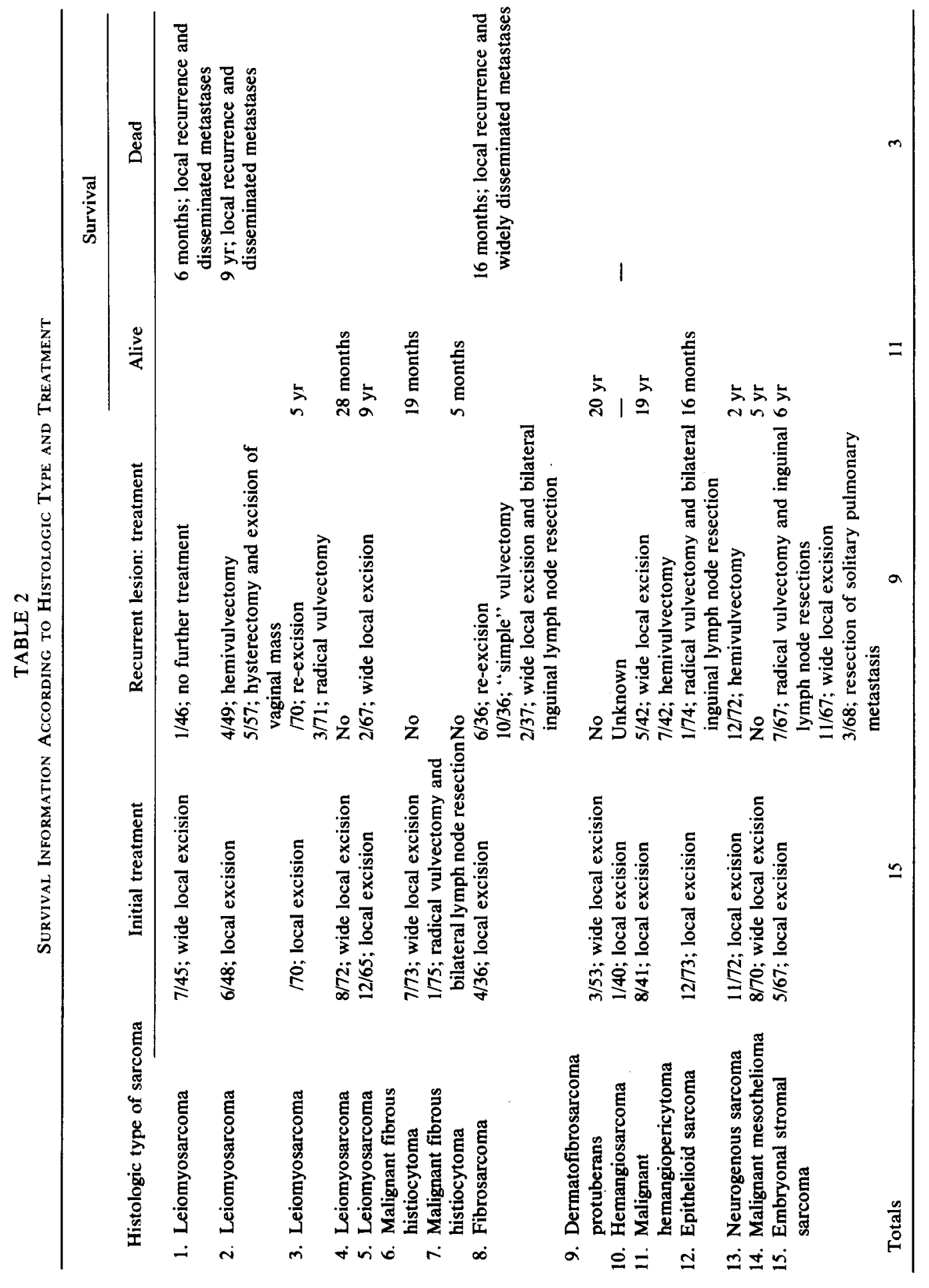




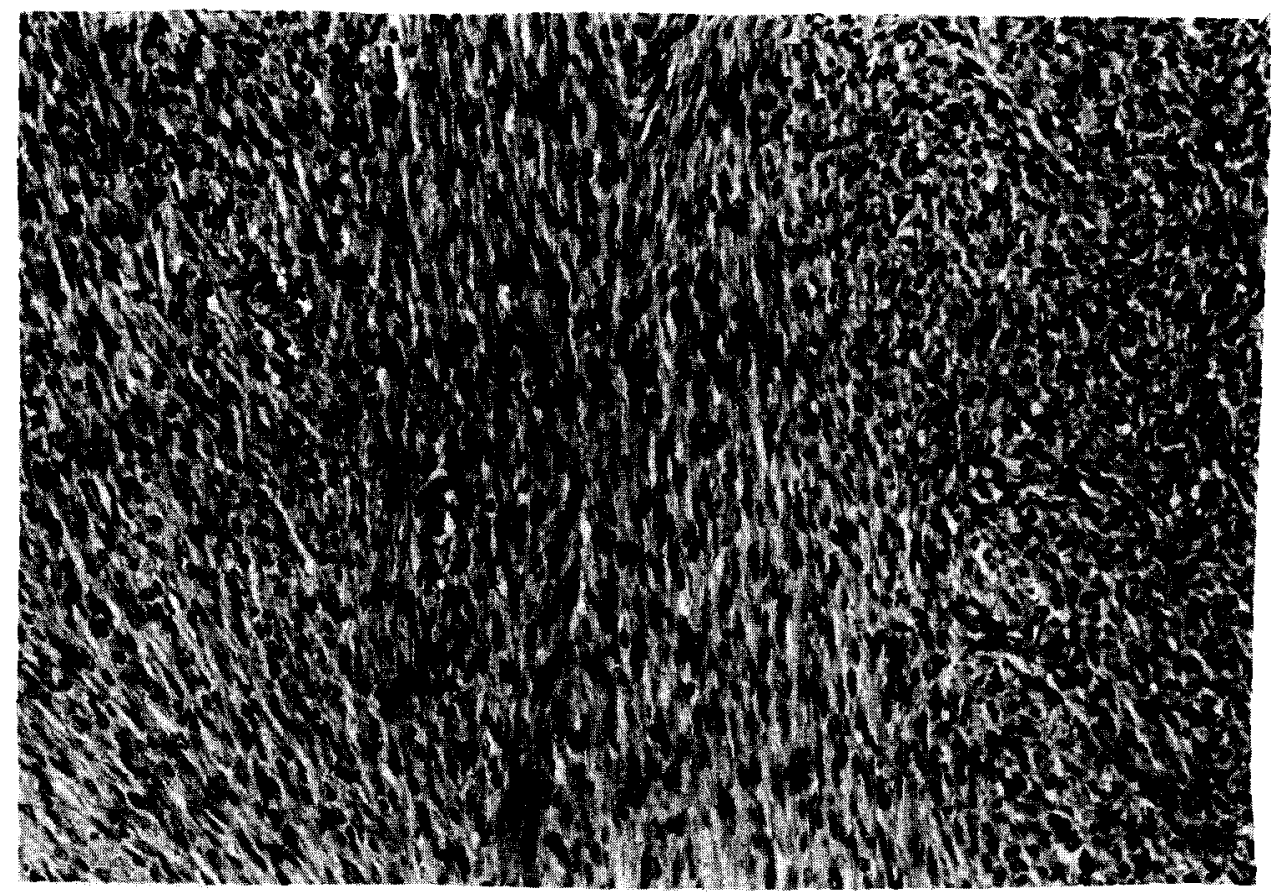

FIG. 1. Leiomyosarcoma with interlacing bundles of slightly pleomorphic, plump, spindled cells. There is hypercellularity and frequent mitoses. Hematoxylin and eosin. $\times 125$.

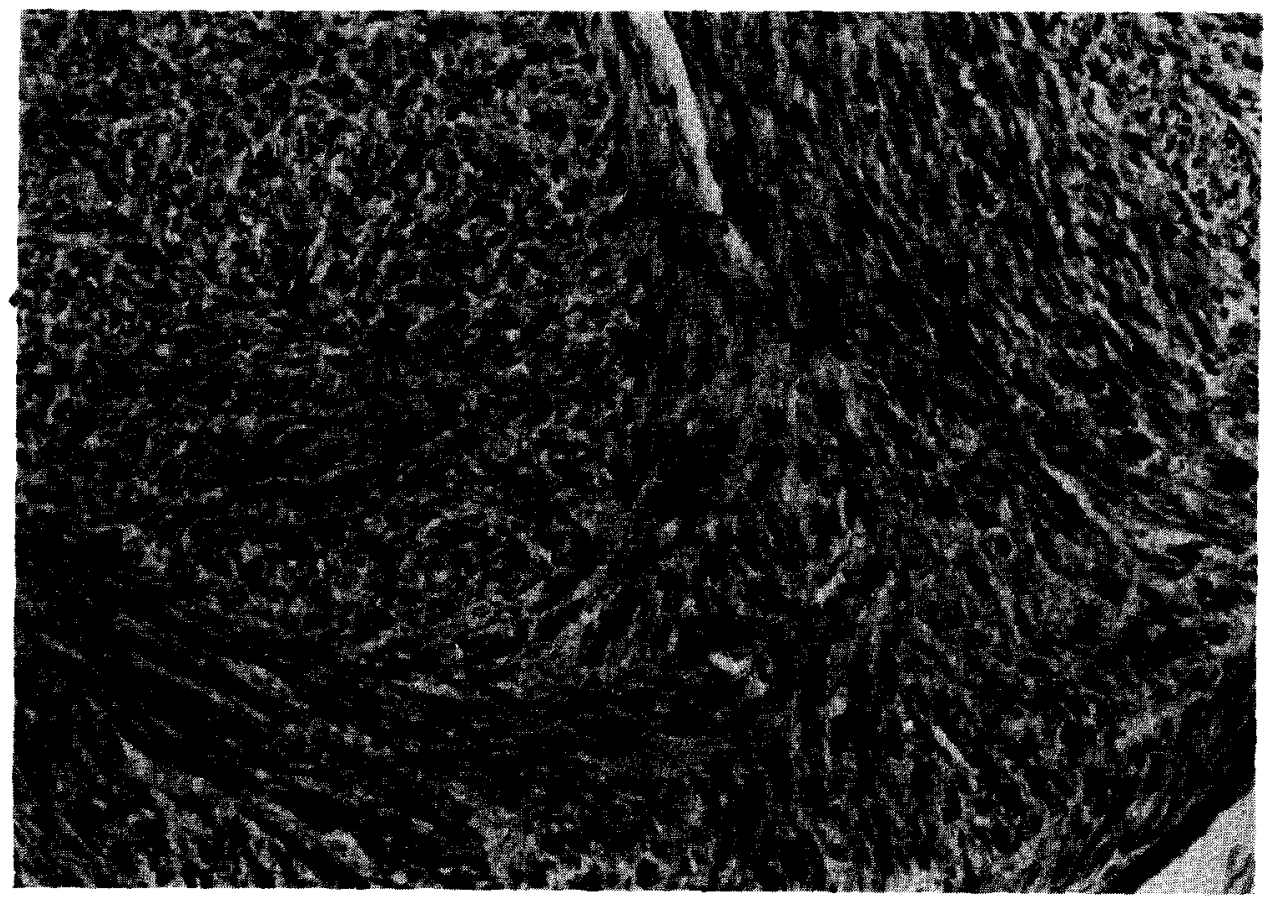

FIG, 2. Leiomyosarcoma. There is moderate cellular pleomorphism and a distinct interlacing pattern of the cells. The nuclei are frequently plump or hyperchromatic with prominent nucleoli and frequent mitotic figures. Hematoxylin and eosin. $\times 200$. 


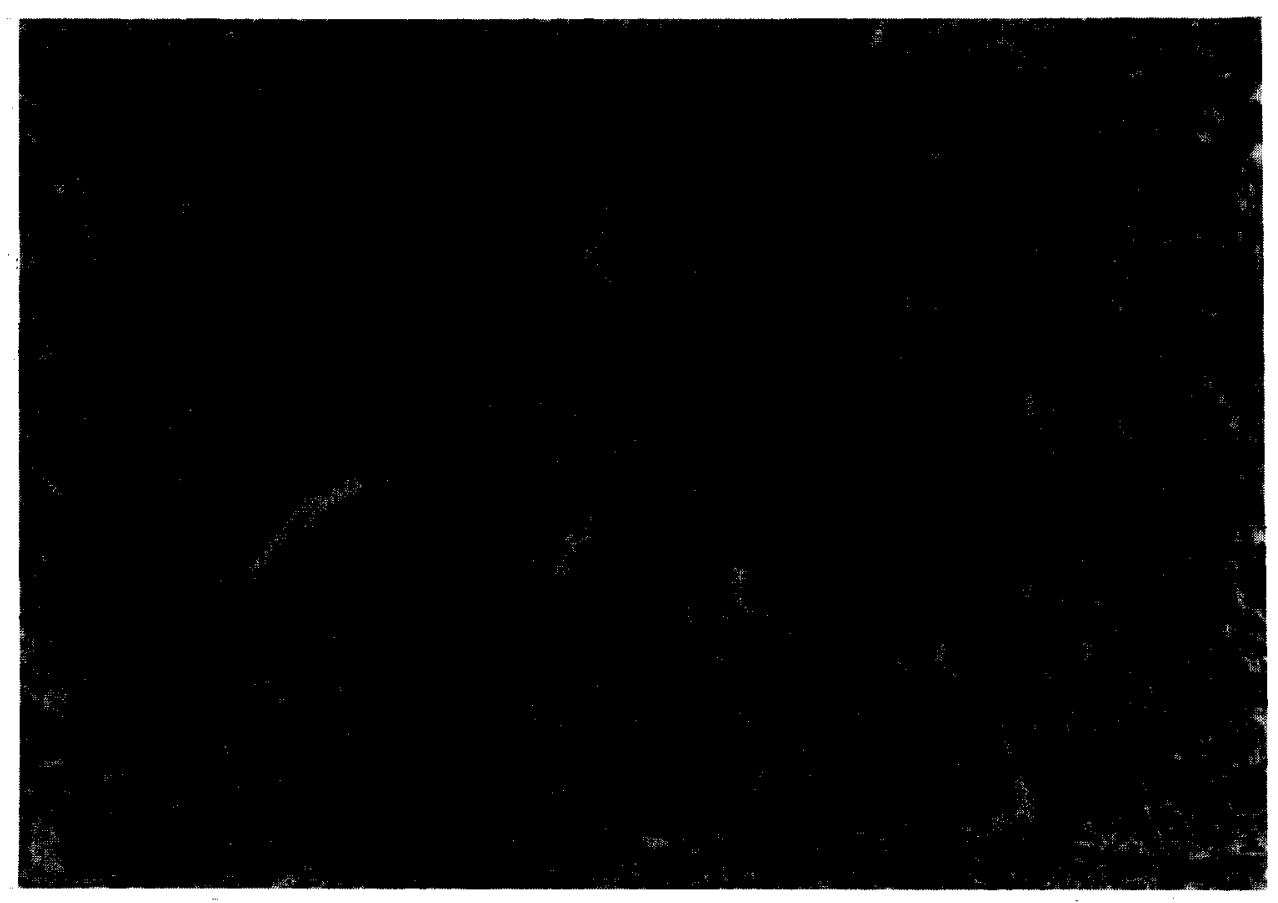

Fic. 3. Malignant fibrous histiocytoma from the deep soft tissues of the labium majus. Fibroblastic and histiocytelike cells form haphazardly arranged bundles. The amount of interspersed collagen varies from one area to another. There are several pleomorphic giant cells and increased mitotic figures. Hematoxylin and eosin. $\times 200$.

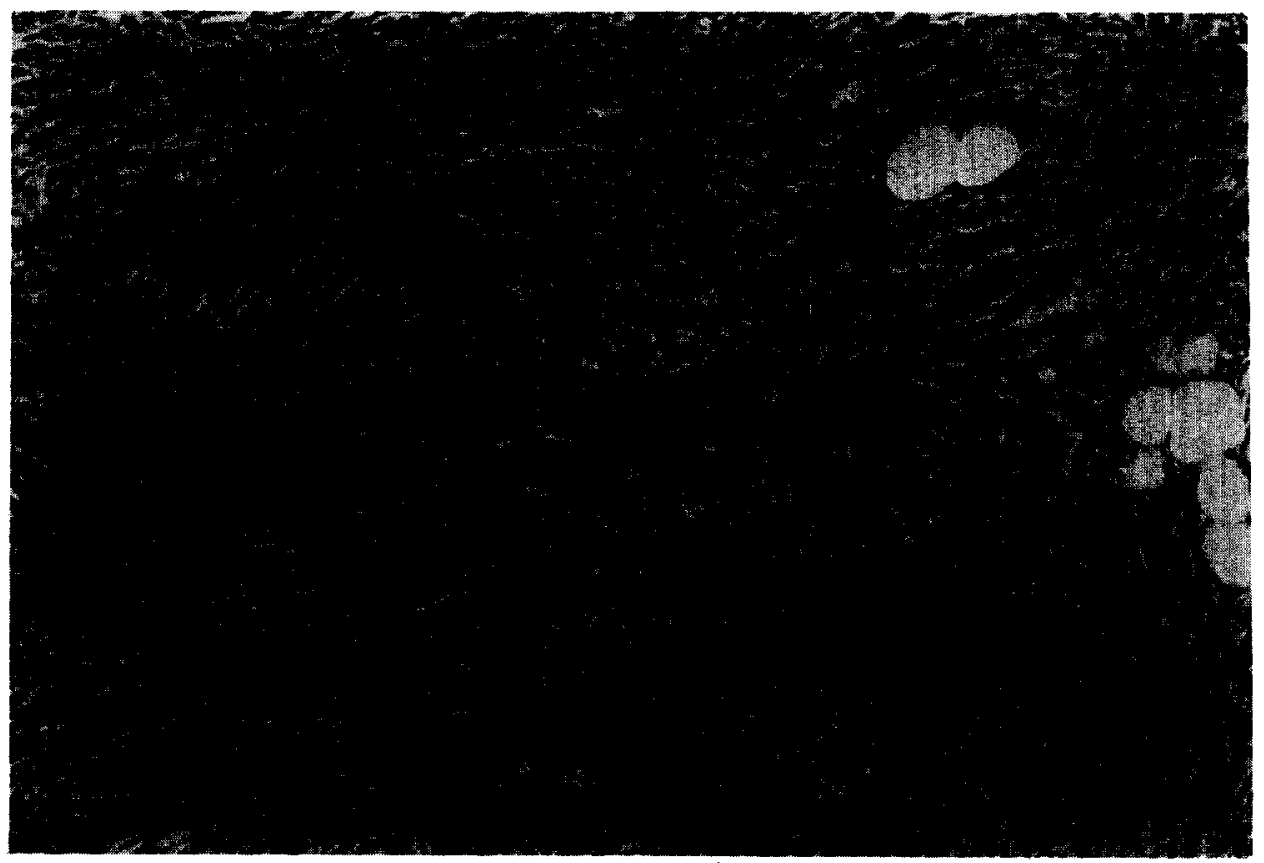

Fig. 4. Dermatofibrosarcoma protuberans with distinct storiform and cartwheel patterns of growth. The cells are hyperchromatic with frequent mitoses. There is infiltration of the subcutaneous adipose tissue. Hematoxylin and eosin. $\times 122$. 


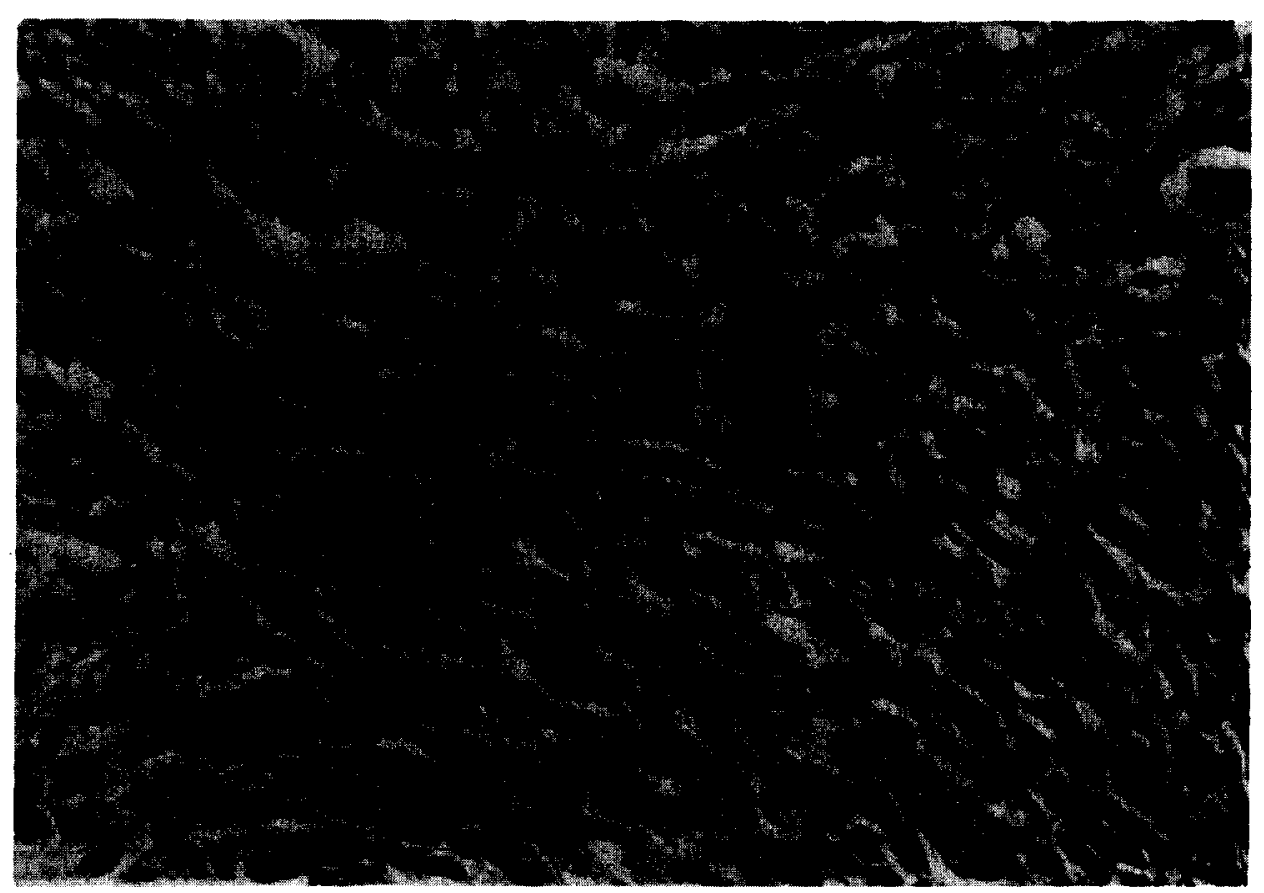

Fig. 5. Fibrosarcoma with haphazardly arranged bundles of spindled and pleomorphic cells with hyperchromatic nuclei and frequent mitotic figures, some of which are atypical. Hematoxylin and eosin. $\times 200$.

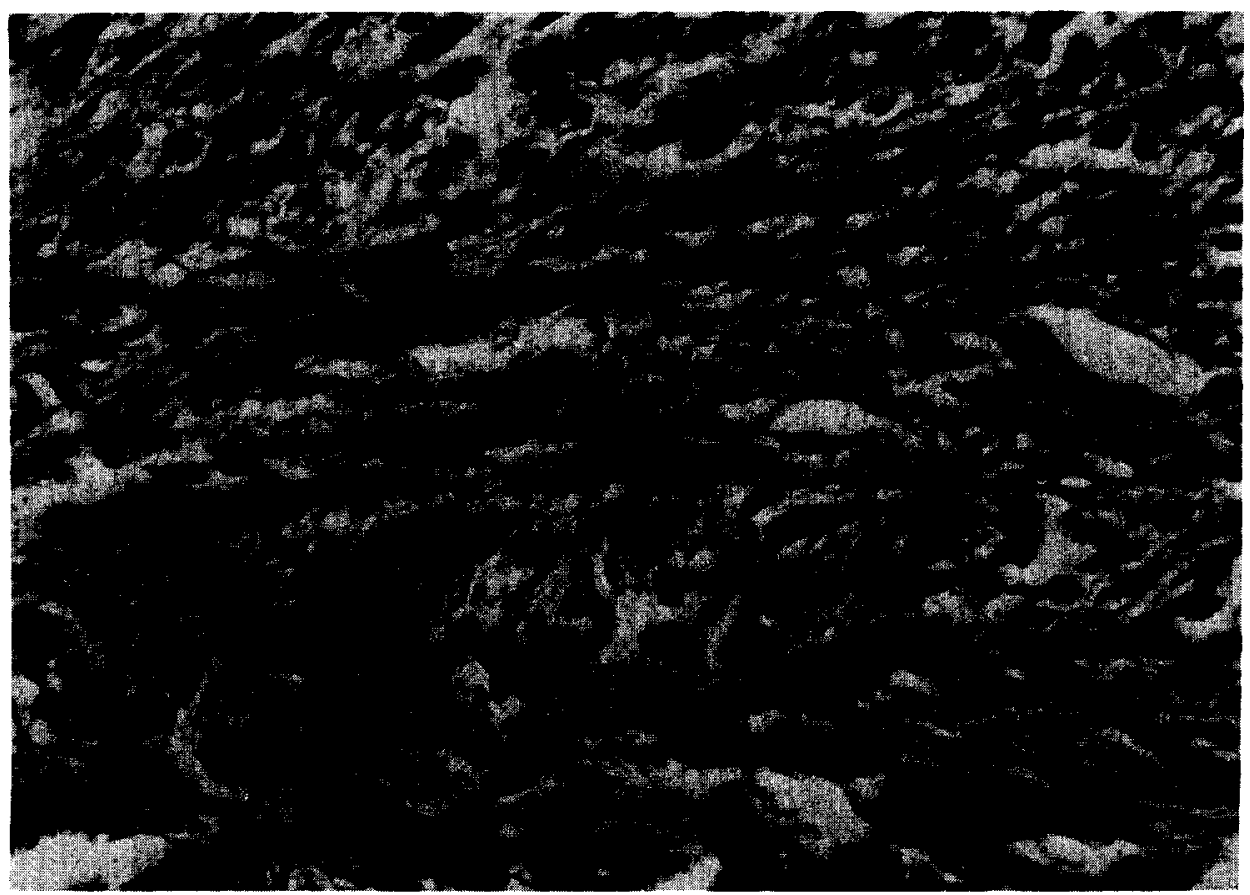

Fig. 6. Trichrome stain (Mallory's stain) for collagen of the fibrosarcoma shown in Fig. 5. Fine strands of collagen have been produced by the neoplastic cells. $\times 313$. 
(Fig. 7). Other areas had a more solid, compact appearance, with interdigitating neoplastic cells, no definite vascular channels, and scanty fibrous stroma. Mitotic figures were variable in number, being focally frequent in some areas and absent in others.

The malignant hemangiopericytoma was a circumscribed, 6-cm tumor in the clitoral region. It consisted of rounded, polygonal, and elongated cells orientated about thin compressed sinusoidal spaces that were more clearly seen in the silver reticulin stains (Fig. 8). The nuclei were large and hyperchromatic, but mitotic figures, although readily found, were not numerous.

The epithelioid sarcoma presented as a slowly growing, deeply placed, $2-\mathrm{cm}$ tumor beneath the skin of the left labium majus. It consisted microscopically of large polygonal epitheliumlike cells with acidophilic cytoplasm and vesicular nuclei (Fig. 9). The cells formed cords, clusters, and medullary sheets with varying amounts of reactive fibroblastic stroma (Fig. 10). There was a central area of necrosis. Cellular pleomorphism was moderate in degree, and mitotic figures frequent. Metastatic neoplasm was present bilaterally in the resected inguinal lymph nodes.

The neurogenous sarcoma (malignant schwannoma) was a $3-\mathrm{cm}$, roughly circumscribed tumor in the left labium majus. A small nodule had been present in this area for several years but had recently increased in size. The patient had no clinical evidence or family history of neurofibromatosis. Storiform and interlacing patterns of growth were formed by closely packed spindled cells with hyperchromatic nuclei and frequent mitotic figures (Fig. 11). These areas blended with a portion of the tumor that was a histologically benign neurofibroma (Fig. 12), indicating that the sarcoma represented a malignant change in a previously existing benign tumor.

The tumor interpreted as a mesothelioma was a $3.5-\mathrm{cm}$ encapsulated soft tumor located in the superior and outer margin of the labium majus contiguous with the round ligament. Its spindled and polygonal cells presented a variety of patterns. In some areas they formed haphazardly arranged bundles; in others they were orientated about dilated sinusoids in a peritheliomatous arrangement. Focal areas of collagenous acidophilic matrix existed among compressed tumor cells (Figs. 13 and 14). The special stains (PAS and alcian blue stains with and without digestion) were supportive but not diagnostic of a mesothelial origin. However, the histologic pattern and the location, together with the histochemical studies, indicate an origin from the process vaginalis peritonei.

The embryonal stomal sarcoma was a 4-cm exophytic lesion of the labium majus. It consisted of sheets of uniform small to medium-sized undifferentiated cells with relatively scanty cytoplasm and indistinct cell membranes. The nuclei were hyperchromatic or vesicular with prominent small nucleoli and frequent mitotic figures. The neoplastic cells diffusely infiltrated the dermis and subcutis (Figs. 15 and 16). Areas of necrosis were present. In some areas the neoplastic cells took on a distinct spindle appearance, and silver reticulin stains revealed fine branching reticulum fibers about individual cells and groups of cells in these areas. The possibility of the tumor being an embryonal rhabdomyosarcoma was carefully considered, but the level of differentiation was such that the diagnosis could not 


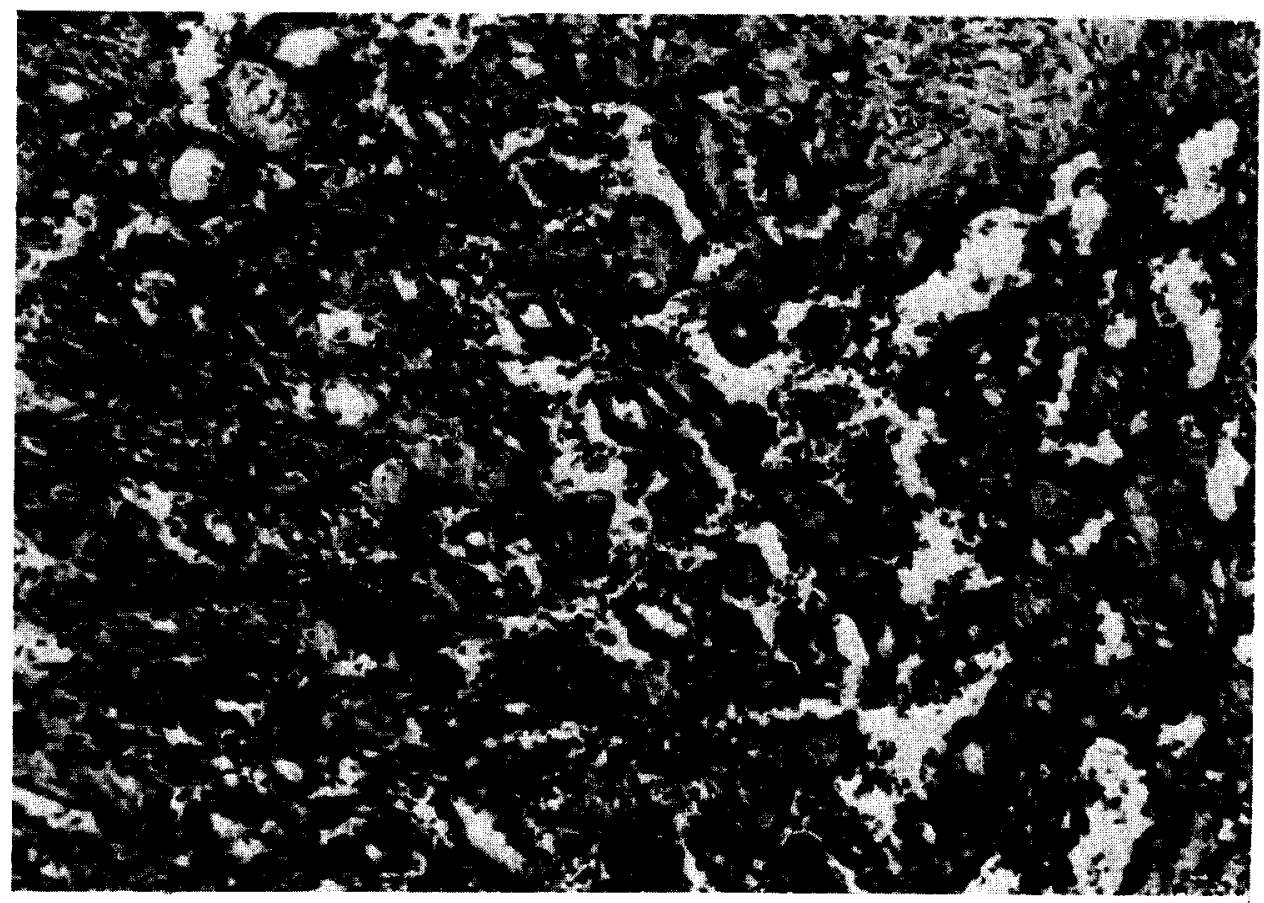

Fig. 7. Hemangiosarcoma with irregular vascular channels and budding and papillary structures. The lining endothelial cells are enlarged with hyperchromatic nuclei. Hematoxylin and eosin. $\times 200$.

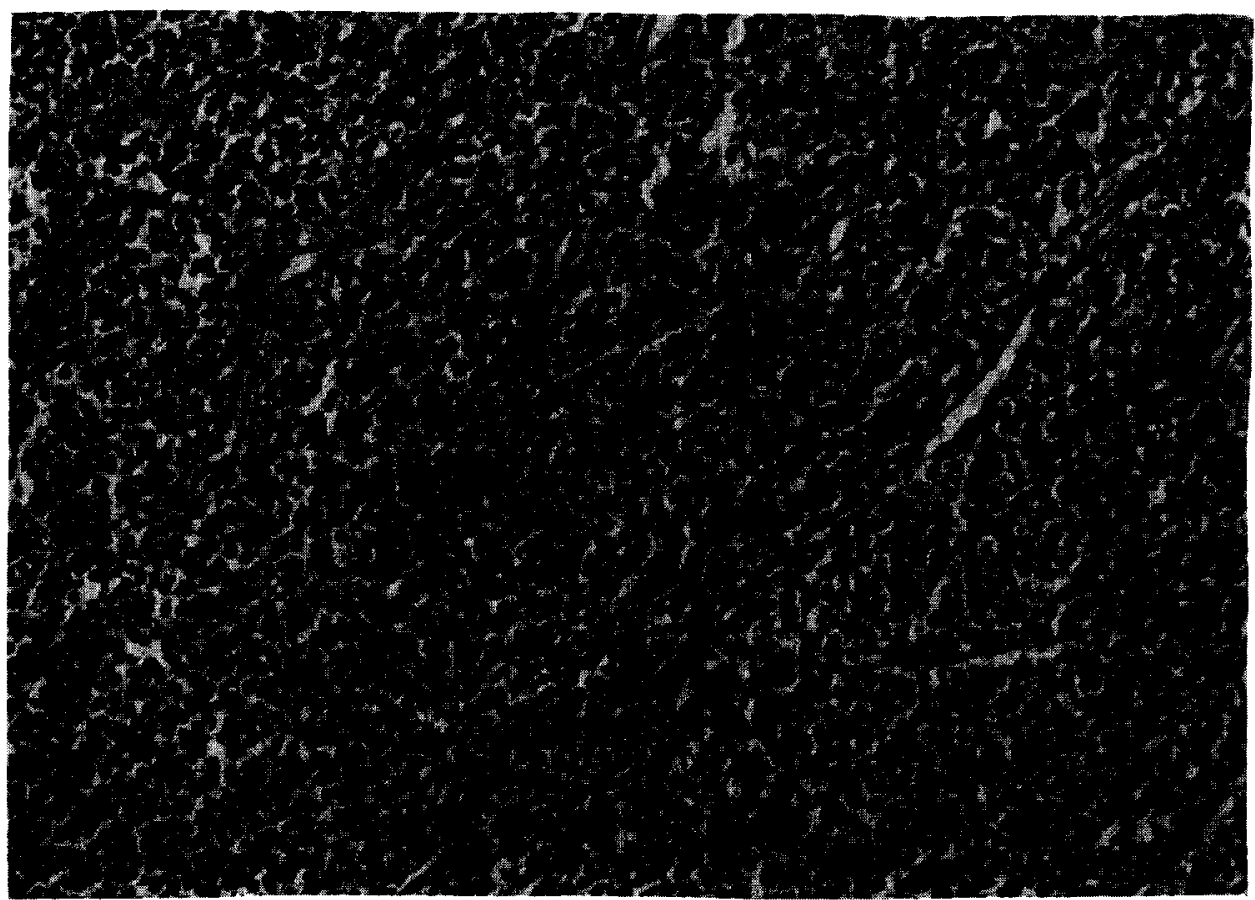

FIG. 8. Malignant hemangiopericytoma with round to polygonal hyperchromatic and slightly pleomorphic cells that are orderly arranged among compressed vascular structures. Hematoxylin and eosin. $\times 125$. 


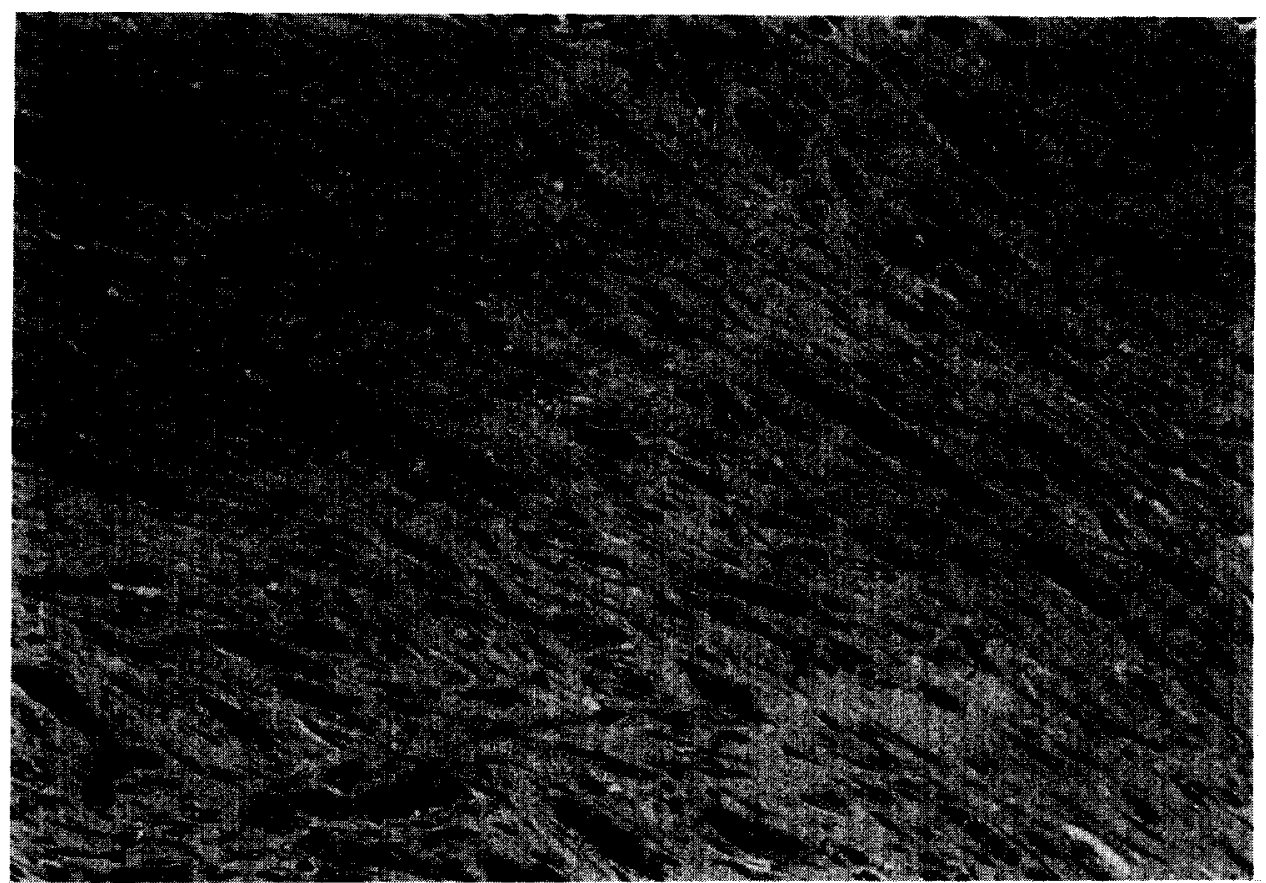

FIG. 9. Epithelioid sarcoma from the deep soft tissues of the labium majus. Within compact collagen are cords and clusters of large, eosinophilic epitheliumlike cells with large vesicular nuclei and prominent nucleoli. There were frequent mitoses and areas of necrosis. Hematoxylin and eosin. $\times 125$.

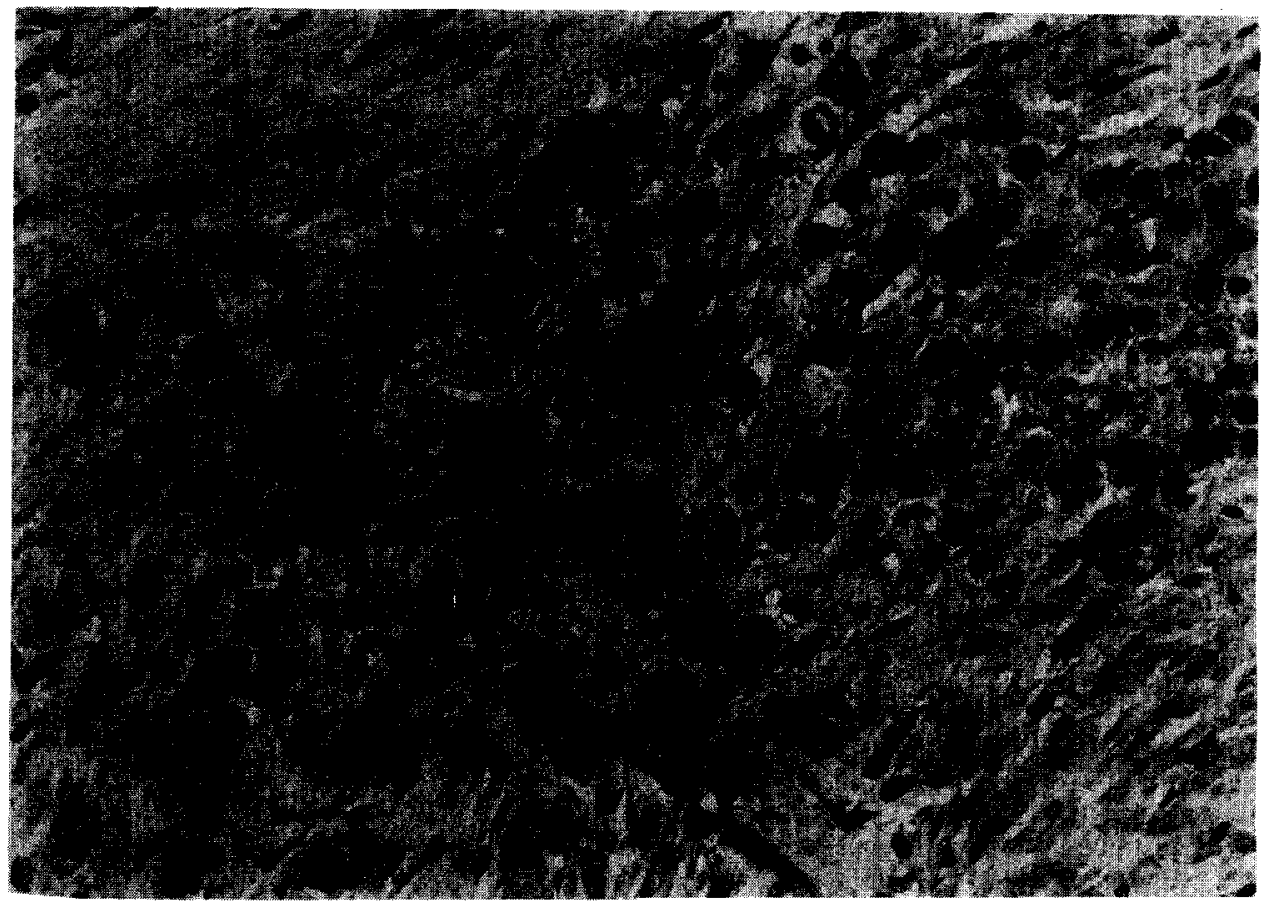

FIG. 10. Higher power of the epithelioid sarcoma shown in Fig. 9. Large, polygonal, epitheliumlike cells form cords and clusters within fibroblastic stroma. Hematoxylin and eosin. $\times 313$. 


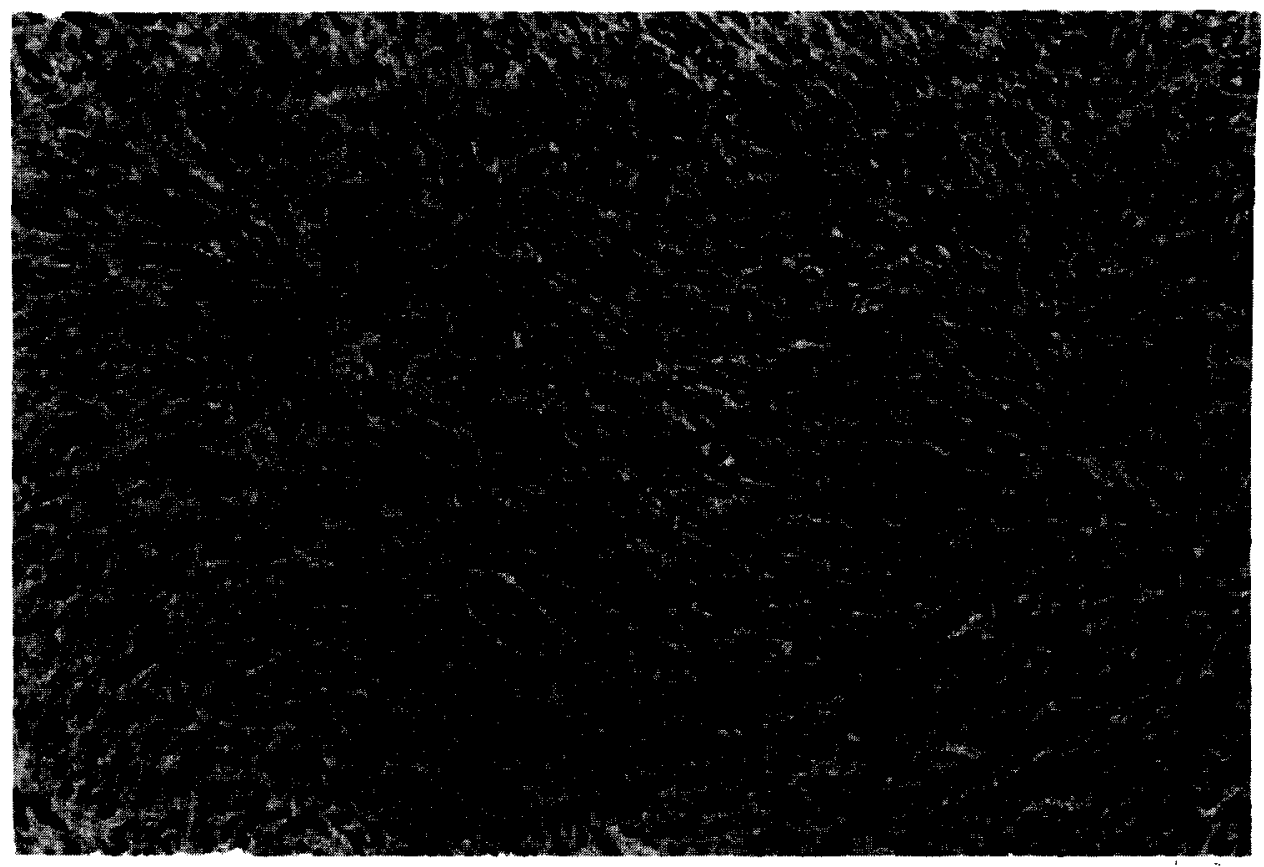

FIG. 11. Malignant schwannoma from the labium majus. There are interlacing bundles of closely packed cells with hyperchromatic nuclei and frequent mitotic figures. There are a few areas with a storiform pattern of growth. Hematoxylin and eosin. $\times 125$.

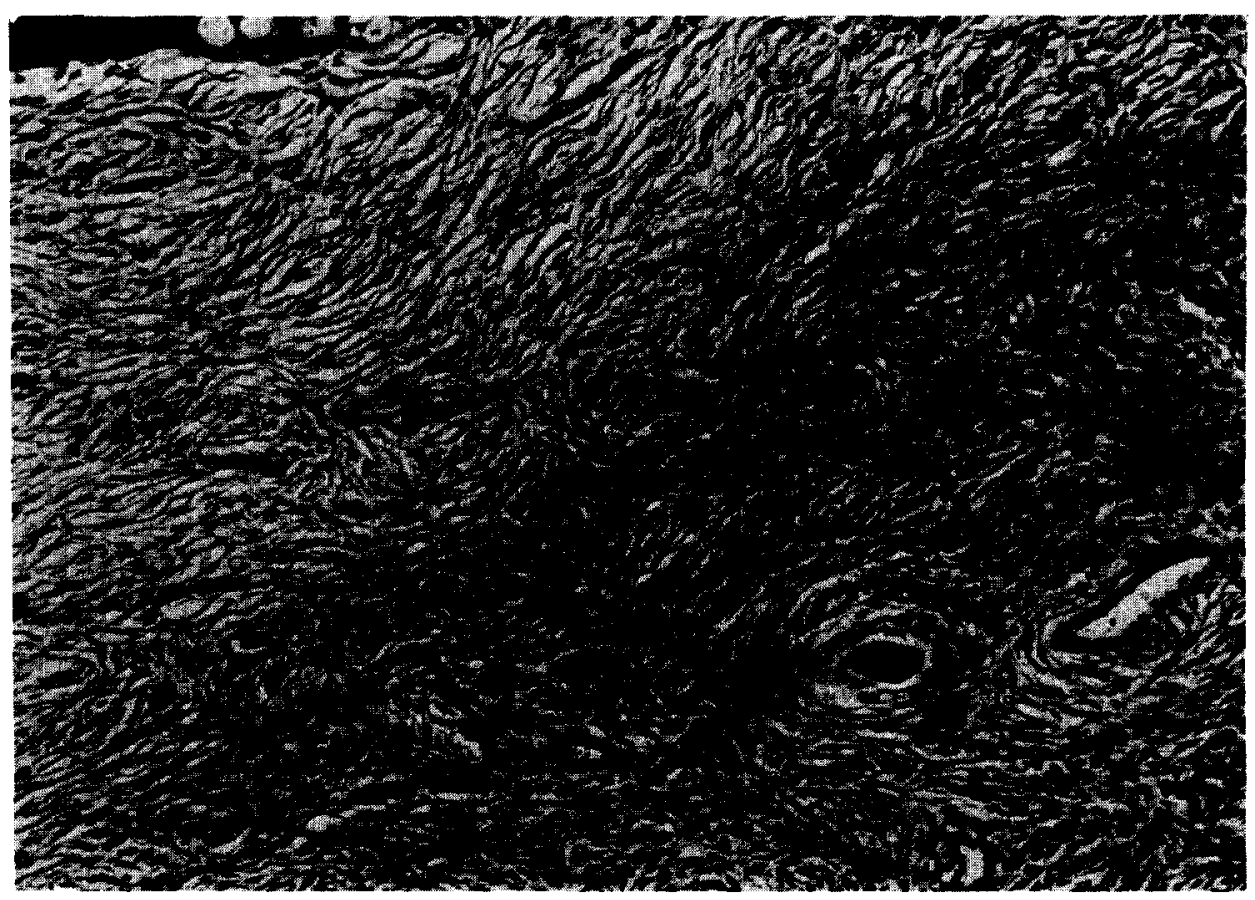

FIG. 12. Sections from the periphery of the malignant schwannoma, shown in Fig. 11, revealed contiguity and transition from a histologically benign neurofibroma to malignant schwannoma. In the left upper part of the field the cells are uniform and form a storiform pattern of growth. This apparently benign area of neurofibroma is progressively transformed to a malignant tumor with hyperchromatic, pleomorphic, and closely packed cells. Hematoxylin and eosin. $\times 125$. 


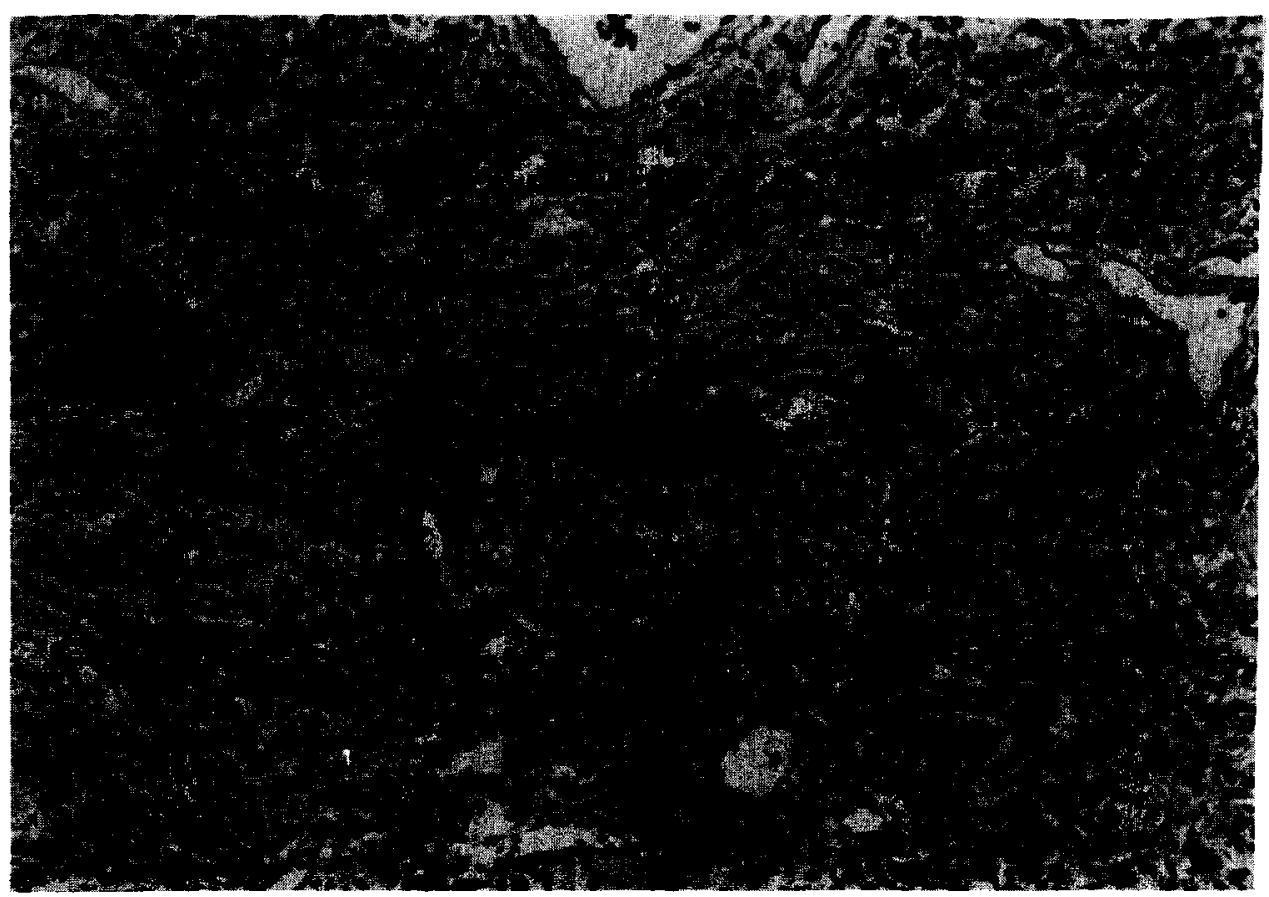

Frc. 13. Malignant mesothelioma with hyperchromatic cells among compact, collagenous, eosinophilic matrix. Within the lesion various sized vessels are numerous. Hematoxylin and eosin. $x$ 125.

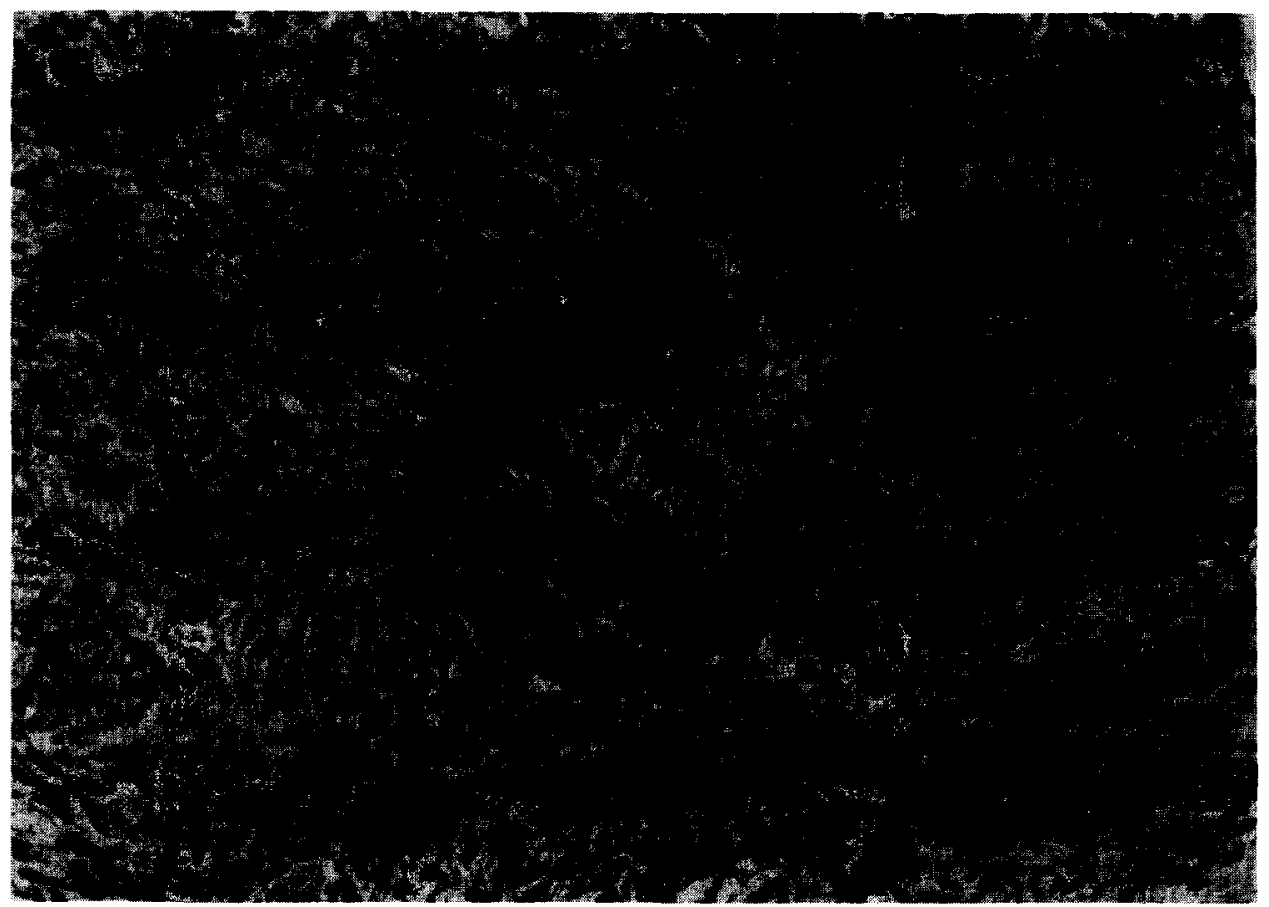

FIG. 14. Higher power of the mesothelioma shown in Fig. 13. There are spindled and polygonal cells with hyperchromatic nuclei arranged in a haphazard pattern. Fine, collagenous, eosinophilic matrix is deposited between clusters of cells. Hematoxylin and eosin. $\times 200$. 


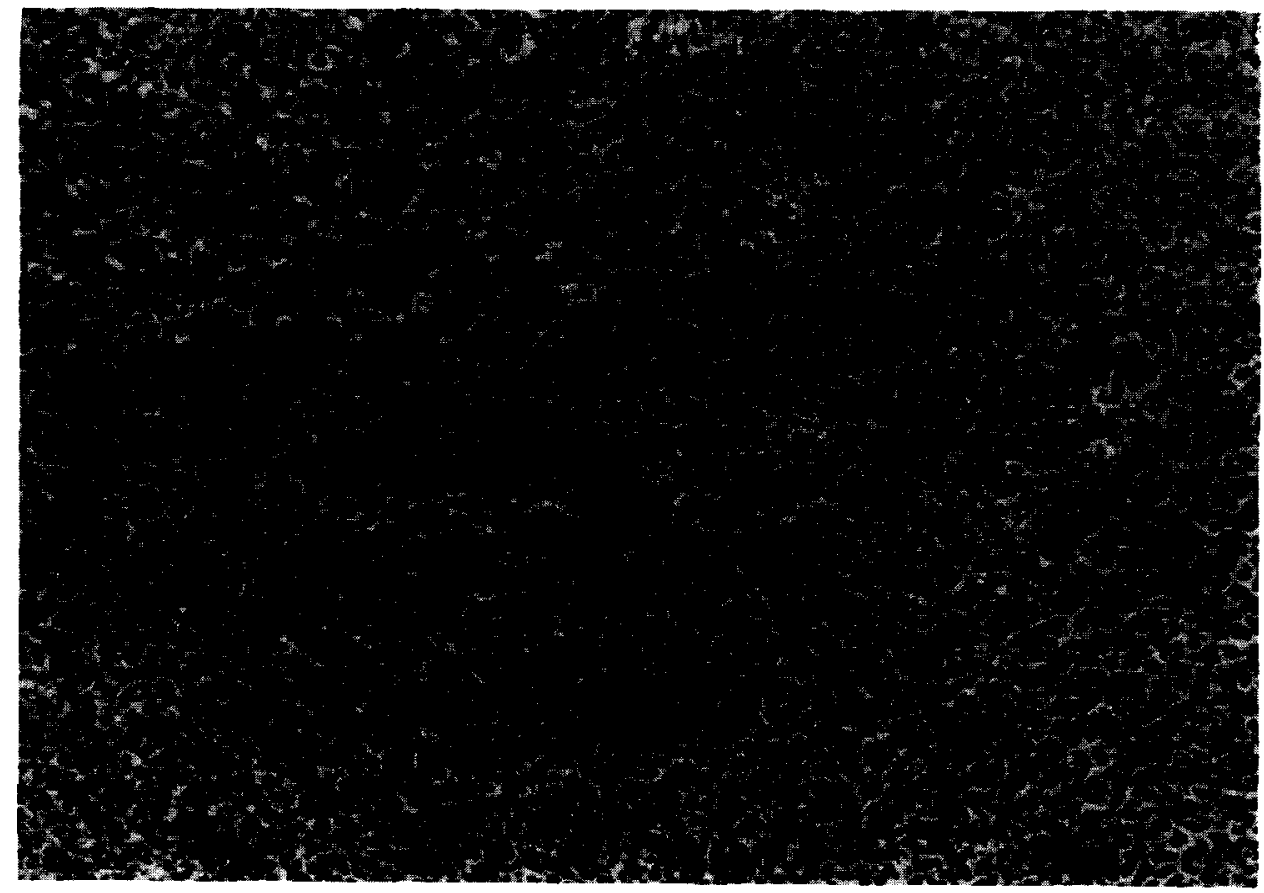

Fig. 15. Embryonal stromal sarcoma of the labium majus arising in the soft tissue and derived from the undifferentiated mesenchyme. There are sheets of uniform small and medium-sized cells with hyperchromatic or vesicular nuclei. The tumor diffusely infiltrated the dermis and subcutis. Hematoxylin and eosin. $\times 200$.

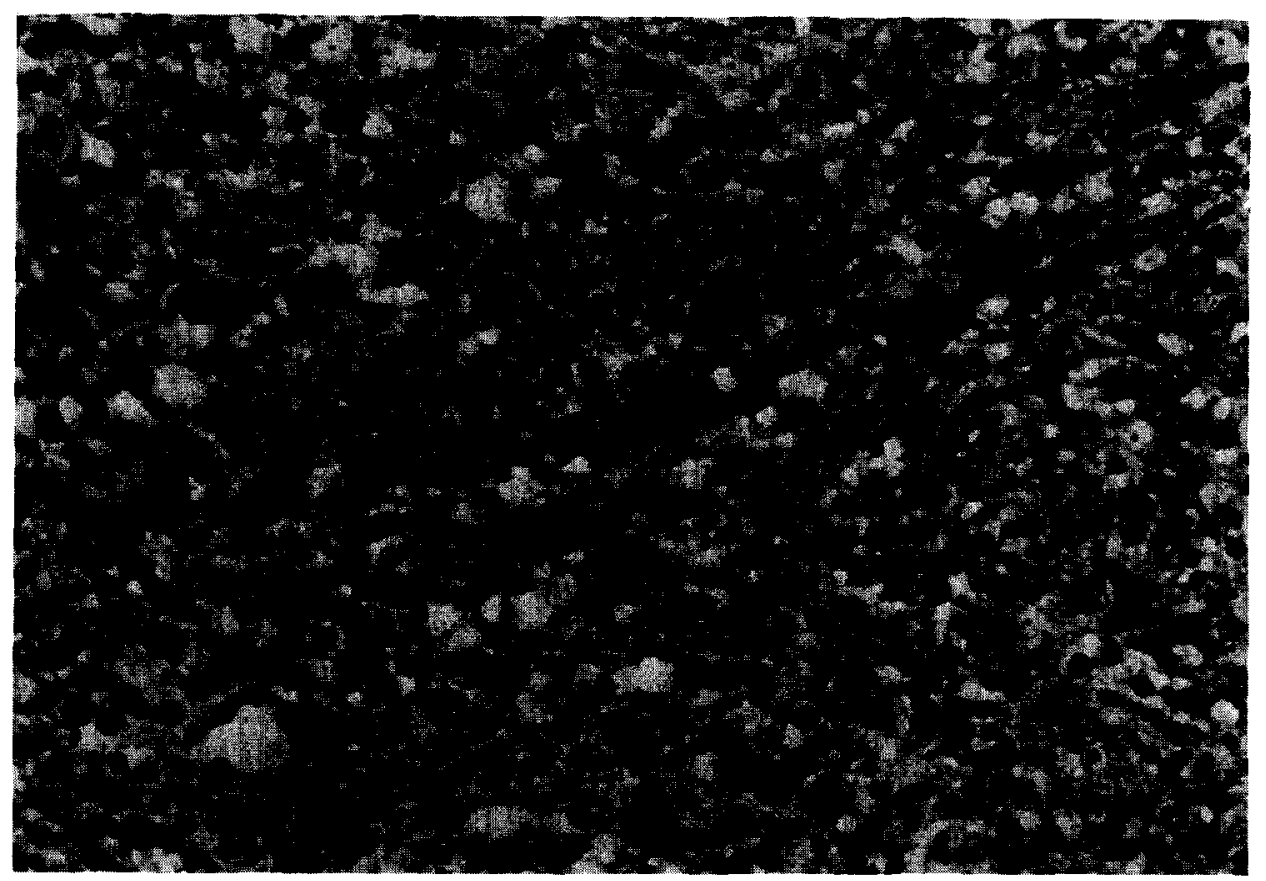

Fig. 16. Higher magnification of the embryonal stromal sarcoma shown in Fig. 15. The cells are slightly pleomorphic with indistinct cytoplasmic membranes, vesicular or hyperchromatic nuclei, and a diffuse pattern of growth. Hematoxylin and eosin. $\times 305$. 
be substantiated. An excised lesion from the right lung 10 months after radical vulvectomy had the same histologic appearance as the vulvar lesion.

\section{End Results}

Eleven of 14 patients for whom survival information was available were alive and clinically free of disease from 5 months to $20 \mathrm{yr}$ after diagnosis (Table 2). The survival periods for six patients were $5 \mathrm{yr}$ or more. Three patients died with local recurrences and hematogenous and lymphogenous metastases. Six of the 11 survivors had local recurrences within a year, which were treated either by radical vulvectomy or extensive local excisions. One of these six had a second local recurrence requiring a third surgical procedure.

Nine of the 13 patients who initially had local excisions of varying width developed recurrences within 18 months that required further surgical treatment. Four of the nine had two or more recurrences. The three patients who died with widespread metastatic disease were treated initially with local excisions.

Five neoplasms, three malignant fibrous histiocytomas, one leiomyosarcoma, and the malignant mesothelioma did not recur after wide local excision or vulvectomy. The longest survivors in the series, 19 and $20 \mathrm{yr}$, were the patients with malignant hemangiopericytoma and dermatofibrosarcoma protuberans. The patient with embryonal stromal sarcoma is alive and clinically free of disease $6 \mathrm{yr}$ from diagnosis, having had an initial local excision, a radical vulvectomy and bilateral inguinal lymph node excisions, excision of local recurrences, and a wedge resection of a solitary pulmonary metastasis. There were four patients in whom the neoplasms at the time of diagnosis were ill defined and infiltrative. All four developed recurrences and three succumbed to their disease.

\section{DISCUSSION}

The small number and the variety of histologic types of sarcoma in this study and the short periods of observation for some patients do not provide adequate information to draw valid prognostic conclusions. However, certain general conclusions can be derived, and when these are combined with the known biologic behavior of the sarcomas in other locations, important and useful information is obtained.

Only three of 14 patients in this series died with widespread metastatic disease during the period of study. Local recurrences in six patients were successfully eliminated by more extensive second surgical procedures. In two patients, in whom inguinal lymph node metastases were found, there has been no further spread of disease since the bilateral inguinal lymph node dissections. One of these patients also had the resection of a solitary pulmonary metastasis.

In general, the overall course of vulvar sarcoma appears to be influenced greatly by the size and the extent of infiltration of the primary tumor. Extensive or radical surgical procedures soon after diagnosis are beneficial, as indicated by the absence of recurrences in all patients in whom such procedures were done. When recurrences developed, they usually appeared within a year and were often successfully eliminated with more extensive surgical excisions.

Leiomyosarcoma was the commonest type of sarcoma in this study, an observation that is in keeping with that of DiSaia et al. [9]. By history, some leiomyosar- 
comas appear to represent malignant change in existing vulvar leiomyomas, but most neoplasms appeared to arise de novo. The majority of tumors are relatively slow growing and insidiously infiltrative and tend to recur and to metastasize by the bloodstream. However, it is evident from this series that late recurrences can develop and that the disease can also follow a short aggressive course. The more superficially located neoplasms tend to have a better prognosis. The results of treatment are more favorable when extensive or radical surgical procedures are employed soon after diagnosis.

The fibrohistiocytic group of sarcomas was second in frequency. Various histologic types of lesions exist within this generic group, and the behavior of the individual tumor depends on the type and location [14-16]. The lesions of skin [17], although anaplastic, rarely metastasize. Dermatofibrosarcoma is a locally invasive tumor, with metastases being very infrequent. They usually appear only after several local recurrences [18-20]. Thus the favorable outcome with the wide local excision of the one lesion in this series would be expected. The course of the more deeply seated tumors is unpredictable in spite of their frequent, very pleomorphic, and bizarre nuclear features. They are, however, prone to aggressive local spread and subsequently to hematogenous metastases. Wide local excision or vulvectomy, as soon as the lesion is diagnosed, is the treatment of choice. Since their course is sometimes unpredictable and prolonged, the short observation period for the two tumors in this series does not permit valid conclusions.

True fibrosarcomas with strands of collagen formation are uncommon neoplasms, and probably a number of the sarcomas so diagnosed in the past were malignant fibrous histiocytomas, fibromatoses, or other histologic types of sarcoma. True fibrosarcomas are aggressive lesions [20], as witness the behavior of the one case in this series.

Vascular sarcomas occur in any part of the body. They are often insidious lesions, not showing much cellular atypism but prone to recurrence, local infiltration, and hematogenous metastases [21]. Extensive local or radical excision is the prefered treatment for both malignant hemangiopericytoma and angiosarcoma.

Epithelioid sarcoma is a distinctive sarcoma with both synovial cell and histiocytic cell features. It is usually found in the extremities of young adults in relation to tendon, fascia, aponeurosis, or periosteum [22, 23]. Prior to the report of this case by Gallup et al. [13], one example had been reported in the vulva [10]. Epithelioid sarcomas tend to grow slowly and to recur frequently. They are capable of metastases both by the lymphatic vessels, as occurred in this case, and later by the bloodstream. Wide local or radical excision with bilateral lymph node resections at an early stage of the disease is recommended.

Neurogenous sarcomas are commonly associated with von Recklinghausen's neurofibromatosis and follow an aggressive course. Malignant transformation of Schwann cells in a benign solitary neurofibroma, as occurred in the tumor in this series, is extremely rare.

The tumor interpreted as a malignant mesothelioma was a well-circumscribed mass in the superior margin of the labium majus contiguous with the round ligament. It may be viewed as a homolog of intrascrotal mesotheliomas [24] and arises from the process vaginalis peritonei or Nück's canal. This particular tumor was 
considered malignant on the basis of nuclear pleomorphism and frequent mitotic figures.

The embryonal stromal sarcoma of the series was similar to stromal sarcomas of cervix and vagina that arise from the substantia propria. It is presumed to have arisen from primitive uncommitted mesenchyme. Although certain features resembled embryonal rhabdomyosarcoma, no histologic or histochemical evidence was found to support such a diagnosis. It is probable that similar lesions have in the past been interpreted as malignant lymphoma. This case is an excellent example of the beneficial results of repeated aggressive surgical treatment in that the patient is alive and clinically free of disease following a local excision, radical excisions of recurrences with bilateral inguinal lymph node resections, and resection of an isolated pulmonary metastasis.

It is clear that the survival of patients with vulvar sarcomas depends on a number of factors, including the predetermined biologic nature of the histologic type, the extent of local invasion when diagnosed, and the type of treatment. Although the treatment may be modified to some extent on the basis of the histologic type and size of the lesion, it is evident from this study that wide local excision or radical vulvectomy with bilateral inguinal lymph node resection is indicated in most instances and gives the best results. In the event of local recurrences, persistent surgical excisions may result in cures, as occurred in several cases in this series that were initially inadequately treated.

\section{REFERENCES}

1. Taussig, F. J. Sarcoma of the vulva, Amer. J. Obstet. Gynecol. 33, 1017-1026 (1937).

2. Bell, W. B. Sarcoma of the vulva including an account of a case of spindle cell sarcoma of the labium minus, J. Obstet. Gynaecol. Brit. Emp. 12, 275-284 (1907).

3. Keller, J. Fibrosarcoma of labium vulvae, Can. Med. Ass. J. 64, 534-536 (1951).

4. Service, A. C., and Derbyshire, R. C. Malignancy of the genitourinary tract in children: Report of a case of sarcoma of the vulva, J. Pediatr. 29, 228-232 (1946).

5. Buckingham, J. C., and McClure, J. H. Reticulum cell sarcoma of the vulva: Report of a case, Obstet. Gynecol. 6, 138-143 (1955).

6. Nolan, R. P. Primary nonpigmented sarcoma of the vulva, with report of a case complicating pregnancy, Amer. J. Obstet. Gynecol. 73, 134-140 (1957).

7. Hyde, W. R. Sarcoma of the vulva: A case report, J. Nat. Med. Ass. 53, $496-498$ (1961).

8. Priore, R. M., Patton, G. D., and Conti, E. A. Pregnancy complicated by nonpigmented sarcoma of the vulva: Report of a case and review of the literature, Obstet. Gynecol. 27, 420-427 (1966).

9. Di Saia, P. J., Rutledge, F., and Smith, J. P. Sarcoma of the vulva: Report of 12 patients, Obstet. Gynecol. 38, 180-184 (1971).

10. Piver, M. S., Tsukada, Y., and Barlow, J. Epithelioid sarcoma of the vulva. Obstet. Gynecol. 40, 839-842 (1972).

11. Hensley, G. T., and Friedrich, E. G., Jr. Malignant fibroxanthoma: A sarcoma of the vulva, Amer. J. Obstet. Gynecol. 116, 289-291 (1973).

12. Lundwall, F. Cancer of the vulva: A clinical review, Acta Radiol. Suppl. 208, 233-236 (1961).

13. Gallup, D., Abell, M. R., and Morley, G. W. Epithelioid sarcoma of vulva, submitted for publication.

14. Kauffman, S. L., and Stout, A. P. Histiocytic tumors (fibrous xanthoma and histiocytoma) in children, Cancer 14, 469-482 (1961).

15. O'Brien, J. E., and Stout, A. P. Malignant fibrous xanthomas, Cancer 17, 1445-1455 (1964).

16. Kempson, R. L., and Kyriakos, M. Fibroxanthosarcoma of the soft tissues: A type of malignant fibrous histiocytoma, Cancer 29, 961-976 (1972). 
17. Kempson, R. L., and McGavran, M. H. Atypical fibroxanthomas of the skin. Cancer 17, 14631471 (1964).

18. Taylor, H. B., and Helwig, E. B. Dermatofibrosarcoma protuberans: A study of 115 cases, Cancer 15, 717-725 (1962).

19. Adams, J. T., and Saltzstein, S. L. Metastasizing dermatofibrosarcoma protuberans: Report of two cases, Amer. Surg. 29, 878-886 (1963).

20. Van der Werf-Messing, B., and van Unnik, J. A. M. Fibrosarcomas of the soft tissues: A clinicopathologic study, Cancer 18, 1113-1123 (1965).

21. Backwinkel, K. D., and Diddams, J. A. Hemangiopericytoma: Report of a case and comprehensive review of the literature, Cancer 25, 896-901 (1970).

22. Enzinger, F. M. Epithelioid sarcoma: A sarcoma simulating a granuloma or a carcinoma, Cancer 26, 1029-1041 (1970).

23. Soule, F. H., and Enriquez, P. Atypical fibrous histiocytoma, malignant fibrous histiocytoma, malignant histiocytoma, and epithelioid sarcoma: A comparative study of 65 tumors, Cancer 30 , 128-143 (1972).

24. Ferenczy, A., Fenoglio, J., and Richart, R. M. Observations on benign mesothelioma of the genital tract (adenomatoid tumor): A comparative ultrastructural study, Cancer 30, 244-260 (1972). 